\title{
How do students succeed in national college entrance examination (Gao-kao) in China: A qualitative study
}

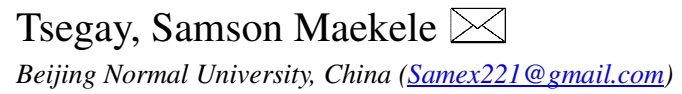

Ashraf, Muhammad Azeem

Beijing Normal University, China (Azeem20037@gmail.com)

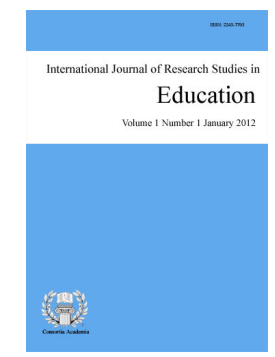

ISSN: 2243-7703 Online ISSN: 2243-7711

\begin{abstract}
This qualitative study examines the factors that affect students' success in National College Entrance Examination (Gao-kao). China has tremendously expanded its education system in the past three decades. A large number of students are being admitted to Chinese Higher Education Institutions (HEIs) using different admission categories. However, Gao-kao has been the dominant means of admitting students in Chinese HEIs since its resumption in 1977, affecting both students' choice of university and program to join. This research explores how Chinese students succeed in this very competitive and important national examination. The study showed that students' success in Gao-kao is the result of different and interrelated factors emerging from the students, with the support of the school and parents. Moreover, the study indicated that students' peer or group discussion could be more advantageous than attending private tutoring. The study contributes in enabling educators in general and students in particular to focus on the effective ways of preparing for Gao-kao and other related examinations.
\end{abstract}

Keywords: Gao-kao; higher education institutions; students' success; schools; parents; China 


\section{How do students succeed in national college entrance examination (Gao-kao) in China: A qualitative study}

\section{Introduction}

National College Entrance Examination (Gao-kao) was started as national college entrance examination in 1952. However, the exam was discarded during the cultural revolution of China (1966-1976) and reinstated in 1977 (Martin, 2012). After its resumption in 1977, Gao-kao has been the main method of school evaluation and means of access to higher education in China. Zhang (2013) noted that Gao-kao is very important step in Chinese students' life to get into Higher Education Institutions (HEIs), and attend a program that they want to study. Albeit the number of students who passed Gao-kao had increased from 1977 (4.1\%) to 2010 (about 60\%), the importance and difficulty of the exam and the intense pressure students feel to perform well have made Goa-kao very special (Martin, 2012). The better score students get in Gao-kao, the better HEIs they can join to study. This is because better HEIs in China take students who have high Gao-kao score. Hence, as it is seen in the 2015 Gao-kao examination, students are doing whatever they can to get good scores, even by illegal means such as cheating and impersonation. This could also be associated with the fact that different provinces need different scores to attend the same university. The lowest qualifying score for students from Beijing and shanghai could be vastly lower than the score required from a student taking the examination in other provinces like Zhejiang province. For instance, the minimum 2008 test score required to join group one regular HEIs for sciences in Shanghai, Beijing and Zhejiang was 467, 502 and 550 respectively (Gu, Li \& Wang, 2009). This is because Chinese provinces have different population and different educational developments including the number and type of universities.

Some provinces such as Beijing and Shanghai have many and prestigious universities; and these universities reserve more places for students with their local Hukou system. The local regular Hukou registration defines one's rights to pursue activities and eligibility for services in a specific locality (Chan, 2009). This indicates that success in Gao-kao is highly influenced by Hukou system. As a result, competition for admission at Chinese top universities is less fierce in Beijing and Shanghai than in other provinces. Students outside of big cities like Beijing and Shanghai have to score high marks and look across the country to get admitted especially in prestigious Chinese universities such as Peking University and Tsighua University. All these factors put students under immense pressure and spend a great amount of time preparing for the exam. Nevertheless, not all students score a pass mark to enable them to join HEIs, and mostly first tier or national key universities. Therefore, it is obvious to ask what factors contribute to the success of students in this important and competitive examination, and how. Gao-kao adopted a " $3+X$ " structure, in which " 3 " refers to the 3 basic subjects (Chinese, Math and one foreign language) and " $\mathrm{X}$ " stands for an integrated competence test such as integrate arts or integrated sciences (Martin, 2012; Gu, Li \& Wang, 2009). For the majority of provinces, a total of 750 points are distributed to the above subjects giving 450 points for the mandatory subjects and 300 points for the X components (Yang, 2009). In this fierce battle for a better future, even few points make a difference.

Different researchers studied different factors (parents, school and socio-economic perspectives) that influence the achievement of students in education. However, these researchers explored the factors from different approaches and perspectives. Contrary to the positive result of parental involvement at home, the study of Chowa, Masa and Tucker (2013) on the Ghanaian youth showed that parental involvement at school is negatively associated with academic performance of students. However, as the data are cross-sectional and observational, the reason for the negative finding of parental school involvement is not clear. In addition, many researchers come out with different and conflicting results on the effects of private tutoring on academic achievement of students. Dang (2007) pointed out that private tutoring increases the probability which student accomplishes good and excellent academic ranking in Vietnam. On the contrary, after studying high school 
How do students succeed in national college entrance examination (Gao-kao) in China: A qualitative study

students who took private tutoring to get good marks in Gao-kao in China, Zhang (2013) stated that there is no real effect of private tutoring on students' academic achievement in urban areas. Therefore, these conflicting research outcomes, and the fierce competition to get a college entrance score, and if possible for the best universities, make this study reasonable to look on how students succeed in Gao-kao. Regardless of the Hukou system, this study will address at how students succeed in Gao-kao. The following research questions will guide the study: (1) what are the factors that influence students' success in Gao-kao? (2) How do these factors influence students' success in Gao-kao? The study will share the experiences of the participants with students and other educators. Moreover, the research will extend the literature on Gao-kao and similar examinations from a qualitative approach.

\section{Factors that affect students' academic achievement}

Different factors ranging from personal preparation to others support and motivation influence student's academic achievement. These factors could be categorized into the following four themes.

\subsection{Family involvement and background}

Family characteristics that influence students' education include family income, parental education, family structure, religion, ethnicity, caste, and parental engagement (Chudgar \& Shafiq, 2010). Each of these characteristics directly influences the time and resources that are dedicated to children's educational outcomes; and in such a way they influence educational outcomes of students. Despite their different nature, parental involvement in students' education can be grouped into a range of school activities aimed at strengthening the overall school program (school involvement) and assisting one's own child at home in informal and in school directed learning tasks (home involvement) (Cai, 2003; Drummond \& Stipek, 2004). Such involvements can be directly through families by themselves or indirectly through other persons such as private tutors. When studying private tutoring in Hong Kong, Hon (2010) stated that families expect academic success from their children and sometimes they set minimum goals such as minimum Gao-kao score for their children, and support them to achieve the goals in different ways. In addition to home support to students, parents participate in meetings, activities, and events at school; and this is motivation both for the students and the school (Kuperminc, Darnell \& Alvarez-Jimenez, 2008). Chowa, et al. (2013) supported this noting that when families challenge students about their schoolwork, students who do not work hard at school begin to work hard because their parents demonstrate that they value education.

On the contrary of positive result of parental involvement at home, Chowa, et al. stated that parental involvement at school is negatively associated with academic performance of students. Moreover, Kuperminc, et al. (2008) discussed the issue of non-traditional forms of parental involvement. This is mainly exposing children to the rigors of manual labor to demonstrate the harsh consequences of not succeeding in school. Parents use such rigor work to enable their children appreciate education and inspire them to a career based on good educational background. However, Katz, Kaplan, and Buzukashvily (2011) argue that students who engage in academic activities because of less adaptive motivations such as a sense of duty, desire to please, and avoidance of punishment tend to achieve less.

Giordano, Phelps, Manning, and Longmore (2008) explained that academic attainment of parents has a major effect on the success of students because educational level of parents influences the financial, social and cultural resources which in turn influence children's cognitive and communication skills, and enhance the material that is taught in the classroom. It is argued that educational level of parents can also lead to educational inequalities (Hanna, Ulrich, Oliver, Marko, Alois, \& Inge, 2012). Parents with lower educational backgrounds could not provide effective educational support to their children. Moreover, Lai, Sadoulet, and Janvry (2009) stated that parents from disadvantaged socio-economic groups have been found to be generally less aware about schools activities. 
Xiaobing, Chengfangu, Linxiu, Renfu, Thomas, Yaojiang, Scott, and Brian (2011) noted that even though China's higher education system is expanding rapidly, students from rural population are still far behind. Globalization has widened the gap between the rich and the poor (Kellner, 2002), where most of the wealth of the world is kept by few people, and in few regions of the world. The characteristics of students and their families have significant impacts on students learning in class and these socio-economic conditions have become increasingly important in determining access to the highest levels of an education system and the most prestigious institutions of learning (Arnove, 2007). Students from better-off families get better education both in regular classes and in private tutoring. In this way children from privileged family backgrounds are more likely to get ahead in school (Hanna et al., 2012). Martins and Veiga (2010) emphasized that the most widespread views are the existence of a strong relationship between socio-economic background and educational achievement. Parents from a high social background are likely to invest more and better in human capital and face fewer credit constraints. Whereas students from poor family background become victim of such inequality because their families may not afford to invest more or stretch beyond their limits to support their children to achieve higher grades (Dang, 2007).

\subsection{School background}

Similar to family background, school background has also been a major concern to researchers who believe that there is high relationship between schools and students' academic achievement. Martins and Veiga (2010) noted that schools contribute to the socio-economic related inequalities more than parents, by transforming social hierarchies into academic hierarchies. These hierarchies can be revealed in different school variables related to organization, school environment, and quality of resources. These variables include the quality of different school resources including the quality of teachers and teaching methodologies within the school that contribute to students' achievement in various interconnected ways such as by nurturing participatory teaching-learning, internal motivation as well as guidance and evaluation of the studies and progress of students (Tsegay \& Ashraf, 2015).

Given the great differences in school resources mainly in developing countries, rural schools and many urban ones may not have adequate and quality facilities and equipment such as enough textbooks and competent teachers (Arnove, 2007); and this can make a great difference in the outcome of students' results. Therefore, it could be argued that better school variables can contribute significantly to students' success rate. Whereas students in lower quality schools subsequently obtain lower test scores as it is seen on the High School Entrance Examination (Lai et al., 2009). This indicates that students in schools with unfavorable socio-economic status score comparatively less results.

\subsection{Private supplementary tutoring}

Private supplementary tutoring (Shadow Education) is basically meant to supplement students' activities in the mainstream education. It is a reflection of the mainstream one in the sense that it follows the footsteps of the mainstream education, and it changes when the mainstream education system changes. Private tutoring has become very important part of exam-based curriculum. Parents and students are paying more attention on private tutoring to get higher marks in exams. According to Bray (2013), significant growth and spread of private tutoring has been seen around the world. These tutoring are usually arranged at home, in schools or any other facilities, individually or in groups. Bray (2013) further explained that private tutoring can create constructive out-of-school activities for students. These constructive out-of-school activities can increase the probability of students in achieving good and excellent academic ranking (Dang, 2007). It is believed that the objective of private tutoring goes beyond improving students' knowledge and skills, to improve their academic achievement. On the contrary, private tutoring also creates heavy economic burden to families, and educational inequalities within societies (Bray \& Lykins, 2012). Therefore, different countries are making different policies to either promote or minimize private tutoring. 
How do students succeed in national college entrance examination (Gao-kao) in China: A qualitative study

After studying on high school students who took private tutoring to get good marks in Gao-kao in China, Zhang (2013) noted that students and parents pay more attention to private tutoring in order to get good marks. However, the study showed that there is no real effect of private tutoring on students' academic achievement in urban areas, but private tutoring has some effect in rural areas. Zhang (2013) attributed this mainly with lack or access of good facilities of education arguing that private tutoring has not effect to students studying in a good school with good facilities. However, private tutoring is important to rural students because they do not enjoy good facilities and depend on the tutoring to compensate the facilities that they lack at their school. It is evident that this study raises concerns about the large input in private tutoring from some parents as many of the attendants of private tutoring are from wealthy families who attend good schools.

\subsection{Students' personal efforts and differences}

Individual differences arise due to different reasons in which some of them are determined by personality or developmental processes (Katz et al., 2011). Forsyth, Story, Kelley, and McMillan (2009) described that students' ability and effort are two of the prominent causes for their educational success or failure. Likewise, Lleras (2008) argued that cognitive skills or abilities, typically measured by standardized tests, have a significant effect in higher educational attainment. Research also showed that participation in extracurricular-school activities, spending time on homework, interest in school, and fewer disciplinary problems were all positively and significantly related to educational success even after controlling socio-economic background of families (Lleras, 2008). It is believed that both students' cognitive skills and non-cognitive behavior such as dedication in school and spending time on academic activities have great effect on students' success. Such factors could compensate the extra academic activities (including private tutoring) that students lack due to their socio-economic and other backgrounds.

It is believed that students need to be inspired to increase their personal efforts. They need to be motivated, guided, and even directed to their goal (Xu \& Mei, 2009). After investigating the role of parents in the quality of motivation that students adopt towards homework, Katz et al. (2011) indicated that when students engage in academic tasks based on intrinsic reasons such as interest, enjoyment, and the purpose to learn and understand, they engage more meaningfully, regulate their learning, and achieve higher grades. This shows that when students are internally motivated, they make high individual efforts and strive for better academic achievement.

\section{Methodology}

This research focuses on factors that determine students' success in Gao-kao from the students' perspective. The research is qualitative in nature drawing on narrative study connecting the individual experiences and the patterns that this study focuses (Luttrell, 2010). Qualitative data was collected from undergraduate students to explore how students succeed in Gao-kao. Face-to-face narrative interview was conducted with 12 undergraduate freshman students who are admitted to first tier university based on their Gao-kao score. Narrative interview was used to allow a series of questions regarding the factors that influenced students' success in Gao-kao and how these factors influenced their success; and create a meaning out of the respondents thinking, perception and imagination (Hollway \& Jefferson, 2008) within the research.

Narrative analysis was used to analyze the data collected through interview. First the data was coded by highlighting the experiences of the students as a whole with the main focus on their Gao-kao preparation and success. Then, representative quotes were added to the coding to develop shared meanings. Finally, narrative analysis is used to understand the experiences of students who succeeded in Gao-Kao (McNabb, 2008).

Investigating the factors that determine students' achievement in Gao-kao will help other prospective examinees and stakeholders to learn from the experience of the previous students. The study may also be applied to other examinations such as regular senior secondary school or university examinations. 


\section{Findings and Discussion}

The result of the interview indicated that many factors contribute to students' success in Gao-kao. They can be categorized into students' efforts and differences, quality schools and parental motivation. Private supplementary tutoring, however, affects students who lack adequate and quality school facilities.

\subsection{Students' personal efforts and differences}

The respondents stated that their personal efforts and differences are important factors in achieving good results in Gao-kao. They believed that if students study hard with definite plan and objectives, it is likely that the students can score a mark to enable them to join HEIs. Despite the variation of study hours within a day, the students noted that they prepared for about 3 years for Gao-kao. Some students stated that they studied for about six hours a day whereas others stayed as long as nine hours a day. It is believed that success in Gao-kao is not the result of two or three years study. It is a summation of all the years that students worked hard. This does not mean that students who studied for two or three years could not pass, but the respondents agreed that students with a continuous learning habit are likely to have greater advantage to succeed in Gao-kao. Moreover, the result of the interview indicated that Gao-kao is not completely new examination. It is the replication of the previous examination with a slight change. The system is almost the same and some of the questions are similar to school examinations which can be practiced with the help of books, internet and other resources. One of the respondents who joined tier one university with a Gao-kao score of 648 from Jilin province noted:

In today's world there is nothing that cannot be found online. I used the internet to practice different questions, do assignments and read different Gao-kao related materials. Then, this helped me to familiarize with Gao-kao related questions and prepare for the big Gao-kao examination.

The above statement indicates that practicing previous years Gao-kao and other related examinations is an advantage especially as a pre-test for self-assessment and for the actual Gao-kao examination.

Moreover, the response from the students reiterated that there is personal difference within students which leads to excellence of students in a particular or many subjects. The students believed that some students are better than their colleagues in some subjects. One of the respondents who scored 652 in Gao-kao noted:

I was one of the best students in Mathematics in my high school. I even participated in Mathematics competition in my city and stood second. Therefore, I had no doubt that I will score better grade in Mathematics than my colleagues.

Another respondent also said:

I am an intelligent student. I proved this in my entire high school studies by getting different prizes including the best student and the best class monitor prizes; these prizes show my intelligence and responsibility which was the base for my Gao-kao success.

The students' perception was that their personal difference affects their way of preparing for Gao-kao including choosing of study materials, method of studying, and number of study hours. The students believed that more number of study hours does not necessarily mean effective way of studying. The respondents explained that students need to be systematic by spending more time to subjects which are difficult for them and less time for subjects that they are good at. Besides, the students stated that reflective study is better than rote memorization especially in preparing for Gao-kao because students need to read a lot of contents and reflective study can help them to understand the content so that they could not forget it easily.

It can be argued that students' personal difference can be manifested in the effort that they do to achieve their goals; and this could be due to the differences in time that students spend in studying and/or their way of 
How do students succeed in national college entrance examination (Gao-kao) in China: A qualitative study

studying. Some students study for about six hours a day while others prepare for about nine hours. The difference can also be seen in the excellence of students in one subject or their difficulty in another one. This idea is consistent with what Forsyth et al., (2009) and Lleras (2008) described that students' ability and effort are two prominent causes for their educational success or failure. Therefore, students can make a change if they can identify and exploit their strengths and weaknesses. Students can spend much time and work hard in subjects that are hard for them and may also request for further help form their teachers and classmates. It is believed that without students' participation and dedication, any effort from anyone could be worthless.

\subsection{Group Study}

The interview findings revealed that group study is an input for Gao-kao success. Peer or group study helps students to discuss and support each other. Different students can have different capacity levels to a certain subject matter. Therefore, when students cooperate and study in groups, they discuss and tutor each other. An interviewee explained:

I was studying with my classmate; we were discussing on many issues including the content to be studied, materials to be used, method of studying, and others. Besides, we were studying together and practicing different types of Gao-kao questions. I was tutoring my classmate Mathematics and she was supporting me in English. It was a mutual cooperation and a win-win system in both ways. When you teach to someone or being taught by someone, it is all learning.

The above excerpt shows that students are different from one another; if students can exploit these differences in a positive and mutually beneficial ways, it could help to boost their academic achievement. Students can engage in conversation about studying, assignments and other academics with their classmates. They can also help each other by sharing knowledge, experience and materials related to the exam. It is argued that students are more comfortable to engage each other and discuss freely more than they might do with teachers; and this could contribute for better learning and higher Gao-kao achievement. However, it is important to note that students need to choose their study partners carefully, considering their goals and other personalities.

\subsection{Quality schools}

The students articulated that their schools are one of the factors that influenced their Gao-kao success. The respondents explained that a good school is characterized by good instructional resources, good management and most importantly quality teachers that can motivate and engage students. Many of the students stated that they studied high school in a better school compared to their region. A respondent said:

I studied in one of the best high schools in my province. The school was well equipped with necessary resources including teaching materials and teachers. The school also had comparably good students which I was able to work with and share my knowledge. Then all these conditions were very important for my success in Gao-kao.

This statement confirms that schools have vital role which is of crucial importance for future academic achievements of students (Lai et al., 2009; Arnove, 2007). On the other hand, it also shows that schools are creating educational gaps which extend to socio-economic and political situations as children from privileged family and urban areas go to better schools and get better educational services (Martins \& Veiga, 2010). Moreover, the study showed that quality schools can compensate the need for private tutoring. The students stated that working closely with their teachers and classmates is even better than attending private tutoring for Gao-kao preparation. They believed that private tutoring is a waste of time and money, and has very insignificant effect on Gao-kao success. This is because the students do not learn any new things rather than repeating what they did in their school. One of the respondents clearly pointed out this:

I didn't take any private supplementary tutoring, but I know a close friend who took private 
tutoring. It was a repetition of what we were learning in class. It is a waste of time and money. With all the tutoring my friend took, she did not get a mark that could enable her to join any university, even the low level ones.

The above explanation is consistent with the idea of Zhang (2013) which explains that there is no real effect of private tutoring on students' academic achievement in China as far as students use their academic resources such as their teachers effectively. On the other side, the study challenges the findings of Dang (2007) which states that private tutoring increased academic achievement of students in Vietnam. Despite the issue that the need for private tutoring can be compensated with other resources within a school, it is also argued that not all students could attend quality schools for various reasons. In such condition, students can bridge the gap with greater personal efforts and partnership with their teachers and other students.

\subsection{Parental motivation}

It is believed that parents play a crucial role in shaping students in their academic orientation and higher performance. Parental involvement includes not only the general notion of parental monitoring and supervision, but it also encompasses direct and instrumental involvement in academic affairs of the students. The respondents noted that parental involvement especially in the form of supply of educational materials and other facilities, and encouragement is an important factor for students' success in Gao-kao. This indicates that parents directly or indirectly impact the success of students by cultivating a learning habit and self-responsibility for their children. Some of the respondents explained that they studied hundreds of kilometers away from their parents. They were communicating with their parents mainly by telephone. One of the respondents explained her situation:

Though I was not living with my parents during my senior secondary level, they were always telling me that I should work hard to make my future better. In addition, they were always ready to do whatever they could, including morally and financially, to help me succeed in the exam. Then, this shouldered me a great responsibility and motivated me to work hard which greatly contributed to my Gao-kao success.

The above excerpt indicates that parental support and motivation is vital for academic success; and it could also be more effective when it is done based on the students' personal interest and purpose to learn and understand in order to shoulder the responsibility to help themselves (Katz et al., 2011). The motivation and support of parents to enable students to shoulder their responsibility as students is a great input for students' academic success. However, this argument is in disagreement with the idea of non-traditional forms of parental involvement discussed by Kuperminc et al. (2008); putting children to rigors of manual labor as a means of demonstrating harsh consequences of not being successful in school. Different parents could have different understanding on how to motivate their children to work hard academically; and the type of assistance and motivation that parents provide to their children could be greatly influenced by their academic attainment which in turn influences the students' academic achievement (Giordano et al., 2008). Nonetheless, the study showed that external pressure and motivation could not help students to focus on their study. In such condition, students could pretend to be focusing on their study such as reading their books to show their parents that they do care in order to avoid the pressure.

\section{Conclusions and Implication}

Students' success in Gao-kao is the result of comprehensive efforts from different stakeholders such as students, peers, schools, and parents. Although the study did not include the voices of other stakeholders, the study explored the factors that influence students' success in Gao-kao. The study also has an input in resolving the contradictory findings regarding the influence of private supplementary tutoring in students' success in Gao-kao. The study revealed that students do not prefer to attend private supplementary tutoring during their preparation for Gao-kao especially if they have adequate and quality educational resources. The students 
How do students succeed in national college entrance examination (Gao-kao) in China: A qualitative study

perceive that private tutoring can be avoided with school resources and group study.

The study found out that peer or group study is an important factor for students' success in Gao-kao. As students are the prime beneficiary and victims of Gao-kao, their cooperation in using their different skills and helping each other is paramount. Nevertheless, as detailed literature cannot be found related to this issue, it needs further study and investigation.

The study implies that educational institutions should nurture a sense of participatory and cooperative learning to students. It is then that the students can start to help each other in their academic activities including their preparation for Gao-kao. If not, it is obvious to expect students from lower quality schools to lag behind and become victim of the competitive exam; and this becomes worse for children from unprivileged families. Besides, arranging extra classes and creating a positive atmosphere such as providing free classrooms and different Gao-kao related materials could enable students to support each other and score better grades. It also minimizes the pressure for private tutoring and the effect of social status in the examination.

Note: This paper was presented at the "Learning in a Changing World" conference convened by the Institute of Education, University of London and Beijing Normal University from 21-22 November 2014 at Institute of Education, University of London.

\section{References}

Arnove, R. F. (2007). Introduction: Reframing comparative education: The dialectic of the global and the local. In R. F. Arnove \& C. A. Torres (Eds.), Comparative education: The dialectic of the global and the local. (3rd ed., pp. 1-20). Lanham, MD: Rowman \& Littlefield.

Bray, M. (2013). Shadow education: Comparative perspectives on the expansion and implications of private supplementary tutoring. Procedia - Social and Behavioral Sciences, 77, 412-420. http://dx.doi.org/10.1016/j.sbspro.2013.03.096

Bray, M., \& Lykins, C. (2012). Shadow education: Private supplementary tutoring and its implications for policy makers in Asia. Asian Development Bank.

Cai, J. (2003). Investigating parental roles in students' learning of Mathematics from a cross-national perspective. Mathematics Education Research Journal, 15(2), 87-106. http://dx.doi.org/10.1007/BF03217372

Chan, K. W. (2009). The Chinese Hukou system at 50. Eurasian Geography and Economics, 50(2), $197-221$. http://dx.doi.org/10.2747/1539-7216.50.2.197

Chowa, A. N., Masa, D., \& Tucker, J. (2013). The effects of parental involvement on academic performance of Ghanaian youth: Testing measurement and relationships using structural equation modeling. Children and Youth Services Review, 35(12), 2020-2030. http://dx.doi.org/10.1016/j.childyouth.2013.09.009

Chudgar, A., \& Shafiq, M. N. (2010). Family, community, and educational outcomes in South Asia. Prospects, 40(4), 517-534. http://dx.doi.org/10.1007/s11125-010-9169-z

Dang, H. (2007). The determinants and impact of private tutoring classes in Vietnam. Economics of Education Review, 26(6), 684-699. http://dx.doi.org/10.1016/j.econedurev.2007.10.003

Drummond, K. V., \& Stipek, D. (2004). Low-income parents' beliefs about their role in children's academic learning. The Elementary School Journal, 104(3), 197-213. http://dx.doi.org/10.1086/499749

Forsyth, D. R., Story, P. A., Kelley, K. N., \& McMillan, J.H. (2009).What causes failure and success? Students' perceptions of their academic outcomes. Social Psychology of Education, 12(2), 157-174. http://dx.doi.org/10.1007/s11218-008-9078-7

Giordano, C., Phelps, D., Manning, D., \& Longmore, A. (2008). Adolescent academic achievement and romantic relationships. Social Science Research, 37(1), 37-54. http://dx.doi.org/10.1016/j.ssresearch.2007.06.004

Gu L., Li, X., \& Wang, L. (2009). Higher education in China. Hangzhou: Zhejiang University Press.

Hanna, D., Ulrich, T., Oliver, L., Marko, N., Alois, N., \& Inge, S. (2012). Does parental homework involvement 
Tsegay, S. M., \& Ashraf, M. A.

mediate the relationship between family background and educational outcomes? Contemporary Educational Psychology, 37(1), 55-69. http://dx.doi.org/10.1016/j.cedpsych.2011.09.004

Hollway, W., \& Jefferson, T. (2008). The free association narrative interview method. In L. M. Given (Ed.), The SAGE encyclopedia of qualitative research methods (pp. 296-315). Sevenoaks, California: Sage. http://dx.doi.org/10.4135/9781412963909.n182

Hon, H. N. (2010). Hongkong's shadow education: Private tutoring in Hong Kong. The Hong Kong Anthropologist, 4(10), 62-85.

Katz, I., Kaplan, A., \& Buzukashvily, T. (2011). The role of parents' motivation in students' autonomous motivation for doing homework. Learning and Individual Differences, 21, 376-386. http://dx.doi.org/10.1016/j.lindif.2011.04.001

Kellner, D. (2002). Theorizing globalization. Sociological Theory, 20(3), 285-305. http://dx.doi.org/10.1111/0735-2751.00165

Kuperminc, P., Darnell, J., \& Alvarez-Jimenez, A. (2008). Parent involvement in the academic adjustment of Latino middle and high school youth: Teacher expectations and school belonging as mediators. Journal of Adolescence, 31(4), 469-483. http://dx.doi.org/10.1016/j.adolescence.2007.09.003

Lai, F., Sadoulet, E., \& Janvry, A. (2009).The adverse effects of parents' school selection errors on academic achievement: Evidence from the Beijing open enrollment program. Economics of Education Review, 28, 485-496. http://dx.doi.org/10.1016/j.econedurev.2008.10.002

Lleras, C. (2008). Do skills and behaviors in high school matter? The contribution of noncognitive factors in explaining differences in educational attainment and earnings. Social Science Research, 37, 888-902. http://dx.doi.org/10.1016/j.ssresearch.2008.03.004

Luttrell, W. (2010). "Good enough" Methods for life-story analysis. In W. Luttrell (Ed.), Qualitative educational research: Readings in reflexive methodology and transformative practice (pp. 258-278). New York, NY: Routledge.

Martin, O. (2012). China's Gaokao: A new phenomenon or heritage of ancient China? Retrieved from https://www.nshss.org/media/19587/Martin.pdf

Martins, L., \& Veiga, P. (2010). Do inequalities in parents' education play an important role in PISA students' mathematics achievement test score disparities? Economics of Education Review, 29, 1016-1033. http://dx.doi.org/10.1016/j.econedurev.2010.05.001

McNabb, D. E. (2008). Research methods in public administration and nonprofit management: Quantitative and qualitative approaches (2nd ed.). New Delhi: PHI Learning Private Limited.

Tsegay, S. M., \& Ashraf, M. A. (2015). The influence of senior secondary school teachers on students' achievement in Gao-Kao. International Journal of Research Studies in Education, 4(4), 1-10. http://dx.doi.org/10.5861/ijrse.2015.1037

Xiaobing, W., Chengfang, L., Linxiu, Z., Renfu, L., Thomas, G., Yaojiang, S., Scott, R., \& Brian, S. (2011). College education and the poor in China. Documenting the hurdles to educational attainment and college matriculation, 12, 533-546.

Xu, X., \& Mei, W. (2009). Educational policies and legislation in China. Hangzhou: Zhejiang University Press. Yang, M. (2009). Educational system in China. Hangzhou: Zhejiang University Press.

Zhang, Y. (2013). Does private tutoring improve students' national college entrance exam performance? A case study from Jinan, China. Economics of Education Review, 32, 1-28.

http://dx.doi.org/10.1016/j.econedurev.2012.09.008 